\title{
Exploring the Relationships between Media and Political Parties through Web Hyperlink Analysis: the Case of Spain
}

Esteban Romero-Frías ${ }^{a,}$, Liwen Vaughan ${ }^{b}$

:Department of Accounting and Finance, University of Granada, Spain

Campus Universitario de Cartuja, 18071, Granada, Spain. Phone: (+34) 958241000 ext. 20161. Fax: (+34) 958246249, erf@ugr.es

${ }^{\circ}$ Faculty of Information and Media Studies, University of Western Ontario, Canada

Faculty of Information and Media Studies, University of Western Ontario, London, Ontario, N6A 5B7

Canada. Phone: 519-661-2111 ext. 88499, lvaughan@uwo.ca

Corresponding author.

\begin{abstract}
The study focuses on the Web presence of the main Spanish media and seeks to determine whether hyperlink analysis of media and political parties can provide insight into their political orientation. The research included all major national media and political parties in Spain. Inlink and co-link data about these organizations were collected and analyzed using multidimensional scaling (MDS) and other statistical methods. In the MDS map, media are clustered based on their political orientation. There are significantly more co-links between media and parties with the same political orientation than there are between those with different political orientations. Findings from the study suggest the potential of using link analysis to gain new insights into the interactions among media and political parties.
\end{abstract}

Keywords: political parties, Web hyperlink analysis, media, political orientation, Spain. 
Romero-Frías, E. \& Vaughan, L. (2012). "Exploring the Relationships between Media and Political Parties through Web Hyperlink Analysis: the Case of Spain". Journal of the American Society for Information Science and Technology, 63(5): 967-976. Postprint for research purposes.

\section{Introduction}

The Internet has become an essential context within which to study politics (Chadwick \& Howard, 2009) and media (Jenkins, 2006) in our time. Many studies have proven that analyzing Web hyperlinks is an appropriate method for exploring the social and political dimensions of the Web. Numerous earlier studies used Web hyperlink analysis to examine university sites (Smith \& Thelwall, 2002; Tang \& Thelwall, 2003), business sites (Vaughan, Tang \& Du, 2010) and political sites (Kim, Barnett \& Park, 2010; Romero-Frías \& Vaughan, 2010). Relatively fewer studies (Tremayne, 2004; Gao, 2009) analyzed media sites. We have found no study that simultaneously examined both media and political parties through hyperlink analysis, despite the fact that media and politics are often connected and the Web is a platform for both. The purpose of this study is to carry out Web hyperlink analysis of media Web sites to contribute to our knowledge of how link analysis can be used to study media. Specifically, we used Web hyperlink data to investigate the political orientation of various media outlets and the relationship between those media and political parties.

The intersection of politics and media creates a fertile soil for investigating how entities of different natures are connected. As news media is widely viewed as biased by individuals (Baron, 2004), we need to use objective data such as hyperlink data to study connections between media. An inlink, also called a back link, is a link pointing to or leading to a Web page. For example, if page A has a link to page $\mathrm{B}$, then it is an inlink to page B. Further, if page B also has a link to page A, then it is inlink to page A. In this case, there are interlinks between page A and page B. This study uses co-links which is different from interlinks. Co-links are two links on a particular Web page that link to two Web pages belonging to two different sites in the study. For example, if a page has links to the homepages of media A and media B, then media A and media B are co-linked. In contrast to interlink data which are created by one organization to another, co-link creation is not controlled by the organizations but instead reflects, from 
an external viewpoint, the degree of relatedness between the two organizations. Interlinks have a time issue in that the two links have to exist when observed at a particular time. On the other hand, co-links do not have this time issue as the two links exist on the same page. Co-link data have been used successfully to investigate different subjects, such as cultural and linguistic factors (Gouveia \& Kurtenbach, 2009), universities (Ortega \& Aguillo, 2008; Lang, Gouveia \& Leta, 2009), e-science (Park, 2010) and business (Vaughan \& You, 2006; Vaughan \& Romero-Frías, 2010). Building on these previous studies, this research examined patterns of Web linking to the Web sites of Spain's main national media and political parties in order to discover whether Web data reflect the political orientation of media, as well as whether the data can provide insight into the relationship between the media and political parties.

Therefore, our research questions are:

RQ1: Do co-link data reflect media landscape in terms of political orientation?

RQ2: What is the relationship between political parties and media in terms of political orientation?

It should be noted that our research questions refer to media and political parties. When we collected Web hyperlink data, however, we collected data on links to the Web sites of the media and the parties. In other words, the concepts of media and political parties are operationalized by their Web sites. This way of operationalization is necessitated by the nature of Web hyperlinks because Web links are to Web sites.

\section{Literature review}

Research on Internet politics and media is extensive and has been studied from diverse perspectives. This section focuses on some of the main lines of inquiry that could be relevant to our analysis. These include studies on media bias, mainstream media, political studies and studies based on hyperlink data. As our 
Romero-Frías, E. \& Vaughan, L. (2012). "Exploring the Relationships between Media and Political Parties through Web Hyperlink Analysis: the Case of Spain". Journal of the American Society for Information Science and Technology, 63(5): 967-976. Postprint for research purposes.

study analyzes media and political parties in Spain, we also examined some studies that describe the historical connections between media and political power.

Media outlets are consider as biased by some people (Baron, 2004) and different approaches have been pursued to examine the media slant. For example, Groseclose and Milyo (2005) estimated the political orientation (left/right) of media outlets in the U.S. based on the number of citations to think tanks included in the news stories. The political orientation of think tanks was determined based on the number of times the Members of the Congress, for which there are a reputable external measure of ideology, cited them. Gentzkow and Shapiro (2010) measured media bias through a comparison of the language used by Members of the Congress and by outlets' news. However, neither studies used hyperlink or web information in their analysis.

Our study takes place in a context marked by a redefinition of the media industry due to the emergence of information and communication technologies, particularly the Internet. Digital information has radically transformed the media's traditional business model (Casero-Ripollés, 2010), which is based on selling advertisement space on broadcasting media and, particularly for newspapers, on selling print copies. Different studies have addressed the changes that have occurred in journalism since the Internet was integrated into newsrooms, both in the European context (Fortunati et al., 2009) and internationally (Paterson \& Domingo, 2008). These changes in journalistic practices have contributed to the generation of huge amounts of Web data that online research techniques can successfully exploit. For example, Efron (2006) classified political bias (left/right) of web documents and weblogs based on hyperlinks that these documents received. In contrast to previous studies which used a linguistic approach, Efron (2006) modeled political orientation as a social phenomenon and considers that the hyperlink structure can reveal the social communities participating in the phenomenon. Recently Golbeck and Hansen (2011) developed a method to determine the political orientation of the media by analyzing the followers of the media 
Romero-Frías, E. \& Vaughan, L. (2012). "Exploring the Relationships between Media and Political Parties through Web Hyperlink Analysis: the Case of Spain". Journal of the American Society for Information Science and Technology, 63(5): 967-976. Postprint for research purposes.

Twitter feeds. They examined a set of users who followed Twitter feeds of both the U.S. Congressmen and the media. A user's political orientation was determined by which Congressmen he/she followed and this orienttion was then used to determine the political orientation of the media.

In the Spanish context, several papers have addressed the political and media connections. For example, Bustamante (2000) addressed political interventionism in communication policy in this country. Hallin and Papathanassopoulos (2002) described the relationship between media and politics as clientelist. Clientelism is based on relationships of patronage. In this context, media could benefit from political parties through the use of public resources or privileged information and the parties could benefit from the media's ability to generate supportive public opinion. Political clientelism is one practice that could explain media bias in the Spanish context. However, studies show that the existence of media bias is a complex phenomena that depends on different factors such as the maximization of business profit of media (Gentzkow \& Shapiro, 2010). In Spain, as pointed out by Hallin and Papathanassopoulos (2002), there are different media conglomerates which have strong political alliances with the two main political parties (PP and PSOE). Recent books have focused on the role of media in the 2004 Spanish general elections (Sampedro Blanco, 2008; Sampedro Blanco, García Luengo, Vizcaíno Pérez \& Trenzado Romero, 2008). Concerning the media industry, Trillo Domínguez (2008) developed an study of top newspapers in Spain using co-outlink analysis and direct link analysis. They found that newspapers that belong to the same conglomerate tend to link to the same Web sites and thus they form clusters in co-link analysis. Concerning the creation of direct links, newspapers often link to newspapers belonging to the same group. In addition, links between competitors are scarce especially if they are between print newspapers (in contrast to native digital newspapers). The scarcity of links to competitors in the business context was also reported by Vaughan, Gao and Kipp (2006). As media are private business, they try to avoid giving visibility and diverting traffic to competitors' sites by linking to those sites. 
Various studies have analysed media and political issues using Web hyperlink analysis. In the media context, Tremayne (2004) analyzed the use of outlinks in news stories on the Web from a quantitative perspective, showing that its number was increasing over a five-year period. Gao and Vaughan (2005) used a qualitative analysis of inlinks to study the visibility and impact of major newspapers in USA, Canada and China. Gao (2009) analyzed interlinking between People's Daily Online (China) and major U.S. newspapers.

Several studies applied hyperlink network analysis to communication by politicians and other political actors in South Korea (Park \& Thelwall, 2008a; Park \& Kluver, 2009). Park and Thelwall (2008a) analysed the link creation practices of the members of South Korea's National Assembly. Politicians link related Web sites (for example, their party Web site) as a way to reveal their own ideological orientation. Park and Kluver (2009) combined a longitudinal quantitative study of political communication in weblogs with a qualitative interview approach to understand the process of link creation. Another study in the South Korea context (Park and Thelwall, 2008b) determined weblogs political orientation based on the existence of direct links between citizen and politician Web sites. They identified three clusters, two corresponding to the two main political parties and a third cluster made of weblogs connected to both political spheres. Kim, Barnett and Park (2010) analyzed inlinks and co-links to the Web sites of United States Senate members. They found that this type of data is efficient to represent the credibility and reputation of politicians on the Web. Romero-Frías and Vaughan (2010) used inlink and co-link data to study political parties in the European Parliament, showing that left/right wing political orientation was the most significant factor in the linking patterns. However, these studies did not analyze the relationship between political parties and media.

\section{Methods}

\subsection{Selection of media and political parties}


The Spanish Parliament (in Spanish, Cortes Generales) consists of two houses, the Congress and the Senate. The Congress has the power to elect the Prime Minister and is the most politically relevant. All national media in Spain and political parties represented in the Spanish Congress in the 2008 general election are candidates in the study. As the study is based on the political orientations of media at the national level, only the four national parties (PSOE, PP, IU, UPyD) are included in the research. The four parties represented $89.75 \%$ of all the votes in the elections and occupied 326 out of 350 seats in the Congress. Table 1 is a list of the parties, together with the following information: name, URL, results in the 2008 election (collected in December 2010 from the Central Electoral Office Web site, http://www.juntaelectoralcentral.es/), and the number of inlinks pointing to the party's Web site. PSOE and PP are the two main political parties in Spain that are in governing positions at national level. The former is a center-left party that ruled the country from 1982 to 1996 and 2004 to the present. The latter is a center-right party, in government between 1996 and 2004. In 2011 PP is the main opposition party. IU is a left wing party and UPyD is a newcomer that contested for the first time in the 2008 general election. Ideologically, the party incorporates ideas that are traditionally classified either as left or right. In the left to right spectrum, it is located between PSOE and PP.

Table 1. Political parties in the study

\begin{tabular}{|c|c|c|c|c|c|c|c|c|}
\hline \multirow{2}{*}{$\begin{array}{l}\text { Label } \\
\text { in the } \\
\text { maps }\end{array}$} & \multirow{2}{*}{$\begin{array}{c}\text { Name of the } \\
\text { party }\end{array}$} & \multirow{2}{*}{ URL } & \multirow{2}{*}{$\begin{array}{c}\text { Political } \\
\text { orientation } \\
\text { of the } \\
\text { political } \\
\text { party }\end{array}$} & \multicolumn{4}{|c|}{ Results in the 2008 general election } & \multirow{2}{*}{$\begin{array}{l}\text { Inlink } \\
\text { count* }\end{array}$} \\
\hline & & & & Votes & $\%$ votes & Seats & $\%$ seats & \\
\hline PSOE & $\begin{array}{l}\text { Spanish } \\
\text { Socialist } \\
\text { Workers' } \\
\text { Party }\end{array}$ & http://www.psoe.es & Center-left & $11,289,335$ & $44.36 \%$ & 169 & $48.28 \%$ & 220,007 \\
\hline
\end{tabular}


Romero-Frías, E. \& Vaughan, L. (2012). "Exploring the Relationships between Media and Political Parties through Web Hyperlink Analysis: the Case of Spain". Journal of the American Society for Information Science and Technology, 63(5): 967-976. Postprint for research purposes.

\begin{tabular}{|c|l|r|r|r|r|r|r|r|}
\hline PP & $\begin{array}{l}\text { People's } \\
\text { Party }\end{array}$ & http://www.pp.es & Center-right & $10,278,010$ & $40.38 \%$ & 154 & $43.99 \%$ & 267,005 \\
\hline IU & United Left & $\begin{array}{l}\text { http://www1.izquie } \\
\text { rda-unida.es }\end{array}$ & Left & 969,946 & $3.81 \%$ & 2 & $0.57 \%$ & 82,603 \\
\hline UPyD & $\begin{array}{l}\text { Union, } \\
\text { Progress and } \\
\text { Democracy }\end{array}$ & http://www.upyd.es & $\begin{array}{l}\text { Center (Left } \\
\text { or Right) }\end{array}$ & 306,079 & $1.20 \%$ & 1 & $0.28 \%$ & 45,200 \\
\hline
\end{tabular}

The media selected for inclusion in the study are the main traditional media (newspapers, radio stations, and TV stations) that operate at the national level and are privately owned. The national public media corporation (which includes radio and TV stations) was excluded from the study due to the difficulty of determining its political orientation. The media in the study are primarily owned by corporations that also control other media (referred to as a "media group" in the study). The media industry in Spain, which is fragmented in many groups, is currently undergoing many mergers and acquisitions. Therefore, the groups to which the media belong represent the group memberships at the time of data collection, summer 2010. Once the main media groups were identified, we included, when feasible, other relevant media of a different nature (newspaper, radio or TV), if any. The media selected are not native online media but they all have a presence on the Web. All national media are mainly based in Madrid, with the exception of two newspapers published in Barcelona, La Vanguardia and El Periódico de Catalunya, which were included in the study due to their wide circulation in all regions of Spain. The recently created media group Intereconomia was not included in the sample because none of its media entities had a relevant offline presence at the level of the other main media in the study. In short, all main media with a discernible 
Romero-Frías, E. \& Vaughan, L. (2012). "Exploring the Relationships between Media and Political Parties through Web Hyperlink Analysis: the Case of Spain". Journal of the American Society for Information Science and Technology, 63(5): 967-976. Postprint for research purposes.

political orientation and national audience or readership were included in the study. The selection of media was supported by experts in media and political science whom we consulted for the study.

Table 2 lists the media included in the study, together with the following information: label in the maps, name, main URL, type of media, media group, political orientation, and the number of inlinks pointing to the Web site. The labels, designed to facilitate the identification of media in the MDS maps, are made up of a capital letter indicating the media group followed by the type of media: nw (newspaper), rd (radio station) and tv (television). When a media group has more than one entity for each type, the label is followed by a number. The political orientation of media towards political parties was evaluated at a national level. There is no official classification of media as left or right wing, although there is a social consensus regarding the political orientation of the media groups in Spain. For the purpose of this study we needed to determine which media are more supportive of which of the two main national political parties: PSOE (considered as a left wing reference) and PP (considered as a right wing reference). First, we developed a draft version of classification based on social consensus and media editorial lines. Then we interviewed a panel of experts, including academics, politicians and media practitioners, to solicit their views on the classification. We relied on our personal connections to reach this group of experts rather than using a random sampling method to ensure that the experts contacted are willing to participate in this consultation. The seven experts we consulted (four academics, a politician, a journalist and a newspaper director) agreed with each other and with our classification except for two media companies (Enw and Itv) whose classification was controversial. We acknowledge that the number of experts we consulted is small. However, we do not expect the classification to have major changes if we consulted more experts. Our classification was supported by a previous study (Sampedro Blanco, 2008) that examined the political orientation of TV stations in the context of the 2004 general elections. The results show how Antena $3(\mathrm{Htv})$ was more supportive of the political agenda of the conservative party (PP) whereas Telecinco (Itv) and particularly Canal + (main TV station of Prisa group at that time) were more favorable 
Romero-Frías, E. \& Vaughan, L. (2012). "Exploring the Relationships between Media and Political Parties through Web Hyperlink Analysis: the Case of Spain". Journal of the American Society for Information Science and Technology, 63(5): 967-976. Postprint for research purposes.

to the center-left positions (PSOE). Although there are changes in the actors in the current media context, the media groups and their political orientation remain the same. Because our classification is generally agreed by experts and further supported by findings of Sampedro Blanco (2008), we consider it to be reliable enough for the purpose of the study.

Table 2. Media in the study

\begin{tabular}{|c|c|c|c|c|c|c|}
\hline $\begin{array}{l}\text { Label } \\
\text { in the } \\
\text { maps }\end{array}$ & $\begin{array}{l}\text { Name of the } \\
\text { media }\end{array}$ & URL & $\begin{array}{l}\text { Type of } \\
\text { Media }\end{array}$ & $\begin{array}{c}\text { Business } \\
\text { group }\end{array}$ & $\begin{array}{c}\text { Political } \\
\text { orientation }\end{array}$ & $\begin{array}{l}\text { Inlink } \\
\text { count** }\end{array}$ \\
\hline Anw & Publico & http://www.publico.es & newspaper & Mediapro & Left & 634,039 \\
\hline Atv & La Sexta & http://www.lasexta.com & TV & Mediapro & Left & 74,300 \\
\hline Bnw1 & El País & http://www.elpais.com & newspaper & Prisa & Left & $4,471,170$ \\
\hline Bnw2 & Cinco Días & http://www.cincodias.com & newspaper & Prisa & Left & $3,700,576$ \\
\hline Btv1 & Cuatro & http://www.cuatro.com & TV & Prisa & Left & $3,190,585$ \\
\hline Btv2 & Sogecable & http://www.sogecable.es & $\begin{array}{l}\text { audiovisual } \\
\text { holding }\end{array}$ & Prisa & Left & $3,150,287$ \\
\hline Brd & Cadena Ser & http://www.cadenaser.com & radio & Prisa & Left & $3,780,619$ \\
\hline Cnw1 & El Mundo & http://www.elmundo.es & newspaper & $\begin{array}{l}\text { Unidad } \\
\text { Editorial }\end{array}$ & Right & $3,650,624$ \\
\hline Cnw2 & Expansión & http://www.expansion.com & newspaper & \begin{tabular}{|l} 
Unidad \\
Editorial
\end{tabular} & Right & 631,144 \\
\hline Ctv & VEO & http://www.veo.es & TV & \begin{tabular}{|l} 
Unidad \\
Editorial \\
\end{tabular} & Right & 328,006 \\
\hline Dnw & $\begin{array}{l}\text { E1 Periódico de } \\
\text { Catalunya }\end{array}$ & http://www.elperiodico.com & newspaper & Zeta & Left & $2,310,525$ \\
\hline Enw & La Vanguardia & http://www.lavanguardia.es & newspaper & Godó & Left & 846,896 \\
\hline Fnw & $\mathrm{ABC}$ & http://www.abc.es & newspaper & Vocento & Right & $6,200,637$ \\
\hline
\end{tabular}


Romero-Frías, E. \& Vaughan, L. (2012). "Exploring the Relationships between Media and Political Parties through Web Hyperlink Analysis: the Case of Spain". Journal of the American Society for Information Science and Technology, 63(5): 967-976. Postprint for research purposes.

\begin{tabular}{|l|l|l|l|l|l|r|}
\hline Frd & Punto Radio & http://www.puntoradio.com & radio & Vocento & Right & $1,950,255$ \\
\hline Grd & COPE & http://www.cope.es & radio & Cope & Right & 353,021 \\
\hline Gtv & Popular TV & http://www.populartv.net & TV & Cope & Right & 208,000 \\
\hline Hnw & La Razón & http://www.larazon.es & newspaper & Planeta & Right & 304,095 \\
\hline Htv & Antena 3 & http://www.antena3.com & TV & Planeta & Right & 141,016 \\
\hline Hrd & Onda Cero & http://www.ondacero.es & Radio & Planeta & Right & 167,019 \\
\hline Itv & Telecinco & http://www.telecinco.es & TV & Telecinco & Right/Left & 328,064 \\
\hline
\end{tabular}

The classification of two of the media outlets, the newspaper La Vanguardia (Enw) and the TV station Telecinco (Itv), was difficult and controversial. The political orientations of these two media are not as clear cut as those of the other media in the study. Different people may have different views of the political orientation of these media, depending on what factors are considered, e.g. whether the classification is based on regional or national issues (as in the case of the newspaper) or on the political position of the owner or the political stance of news reporting (as in the case of the TV station). After consultation with the experts, we decided to classify La Vanguardia as left wing and Telecinco as unclassified (labeled as right/left in Table 2).

The Web site address of each media entity and political party was collected from Google. For each URL found, we manually checked its correctness and also possible alternative URLs in the form of aliases or redirects. For media with more than one URL, we selected the URL that had more inlinks for data collection. We were forced to select one URL rather than using all URLs for data collection because the complex queries needed to handle multiple URLs were not supported in Yahoo!, the search engine used 
for data collection. The use of only the main URL is a limitation of our data collection. However, this limitation would not have significant impact on our results because most alternative URLs had very few inlinks compared with the main URL. When checked on Nov 30, 2011, inlinks to alternative URLs were only $4 \%$ of inlinks to the main URL on average except the Web sites of La Sexta and Punto Radio. The case of La Sexta will be discussed later in the results section. Punto Radio's alternative URL had large number of inlinks but at the time of data collection in Aug. 2010, it had lower inlink count than the main URL did.

\subsection{Data collection}

In this study, all inlink and co-link data were collected from the commercial search engine Yahoo!. At the time of the study, summer 2010, two other major commercial search engines, Google and Bing, were not able to perform the hyperlink search function required for the study. Google's "link" search query term only retrieves a sample, not the complete set, of inlinks (Google, 2010). Bing's predecessor, MSN Live, suspended inlink search a few years ago. In fact, after the partnership between Bing and Yahoo! took place in the summer of 2010, co-link search queries were no longer supported in Yahoo!'s search interface at www.yahoo.com. Yahoo!'s API still supported the co-link search at that time, so our data were all collected from Yahoo! API on Aug. 10, 2010. . The query syntax of co-link search is shown in Table 3.The "-site:" portion of the queries was used to filter out internal inlinks coming from within the same site or domain. The "www" portion of the URL was truncated to ensure that links to all subdomains were also included.

Table 3. Data collection queries

\begin{tabular}{|c|l|}
\hline To Search for & \multicolumn{1}{c|}{ Query Used } \\
\hline Inlinks to www.abc.com & linkdomain:abc.com -site:abc.com \\
\hline
\end{tabular}


Romero-Frías, E. \& Vaughan, L. (2012). "Exploring the Relationships between Media and Political Parties through Web Hyperlink Analysis: the Case of Spain". Journal of the American Society for Information Science and Technology, 63(5): 967-976. Postprint for research purposes.

Co-links that point to www.abc.com and (linkdomain:abc.com -site:abc.com) (linkdomain:xyz.com www.xyz.com site:xyz.com)

Table 4 includes descriptive information on the hyperlink data collected. The median, instead of the mean, was reported because the hyperlink distribution is skewed.

Table 4. Descriptive statistics for inlink and co-link data collected

\begin{tabular}{|l|r|r|r|r|r|}
\hline & \multicolumn{1}{|c|}{ N } & Median & Min & \multicolumn{1}{c|}{ Max } & \multicolumn{1}{c|}{ Sum } \\
\hline Inlinks & & & & & \\
\hline All organizations & 24 & $492,082.5$ & 45,200 & $6,200,637$ & $37,035,693$ \\
\hline Only Political Parties & 4 & 151,305 & 45,200 & 267,005 & 614,815 \\
\hline Only Media & 20 & $740,467.5$ & 74,300 & $6,200,637$ & $36,420,878$ \\
\hline $\begin{array}{l}\text { Co-links (between all } \\
\text { organizations in the } \\
\text { study) }\end{array}$ & 314 & 9,430 & 12 & $4,250,409$ & $53,193,118$ \\
\hline
\end{tabular}

\section{Data analysis}

The co-link matrices are proximity matrices and there are various ways to analyze proximity matrices. We chose MDS because it serves the purpose of addressing our research questions. The co-link count is a measure of similarity between the two co-linked media. At the macro level, co-links are not created at random. Two media that are related in someway are more likely to be co-linked. For example, two media that took a particular position on a particular issue or reported an event in a certain way are more likely to 
be co-linked by a third party that took the same position. The relatedness of co-linked organizations have been proven by earlier studies of academic (Thelwall \& Wilkinson, 2004) or business (Vaughan \& You, 2006) entities; and we expect this to be true for media as well, i.e. the larger the co-link count, the more likely the two media are related in some way. The PROXSCAL procedure of MDS in SPSS software can analyze a similarity matrix and generate a MDS map that positions data points according to their similarity measure using a heuristic method. The larger the similarity measure, the closer the two data points (in this case the two media) tend to be positioned in the map. Thus we expected that the MDS map would show the media landscape with more similar media located closer to each other. Our earlier study of European political parties also collected co-link data and analyzed the data with MDS (Romero-Frías \& Vaughan, 2010). The MDS maps from that study showed clusters of parties partly based on left and right political orientation. As media also have political orientations, we hypothesized that the MDS map based on co-link data would also show the landscape according to political orientation. To further test this hypothesis, we also collected co-link data with media and major political parties together in the same matrix and generated MDS maps to visualize the relationship between the media and the parties. An added advantage of the MDS analysis is that it produces stress values, which indicate how well the MDS map fits the similarity matrix.

\section{5.- Results}

The section "How media companies relate to each other" reports analyses that involved only media while the section "How political parties relate to the media" reports findings that analyzed media and political parties together. These sections address research question 1 and 2 respectively. In the MDS maps reported below, media and political parties are represented by their labels (see Table 1 and 2). The axes of a MDS map do not have inherent meaning and thus they have no labels in the Figures below. In fact, MDS maps from SPSS output show the two axes as dimension 1 and dimension 2. As explained earlier, MDS works 
Romero-Frías, E. \& Vaughan, L. (2012). "Exploring the Relationships between Media and Political Parties through Web Hyperlink Analysis: the Case of Spain". Journal of the American Society for Information Science and Technology, 63(5): 967-976. Postprint for research purposes.

by positioning data points according to their proximity values (in this study, the co-link counts) and it is a heuristic process. So there is no inherent meaning of the axes.

\subsection{How media companies relate to each other (RQ1)}

This section addresses to research question 1 (RQ1). Figure 1 presents the MDS map with all of the media in the study. The S-stress value of the MDS analysis is 0.123 . According to Norušis $(2010$, p. 345), "Sstress is a measure of fit ranging from 1 (worst possible fit) to 0 (perfect fit)." The value is 0.123 is low and suggests a good fit between the map and the data.

Figure 1. MDS map for all media

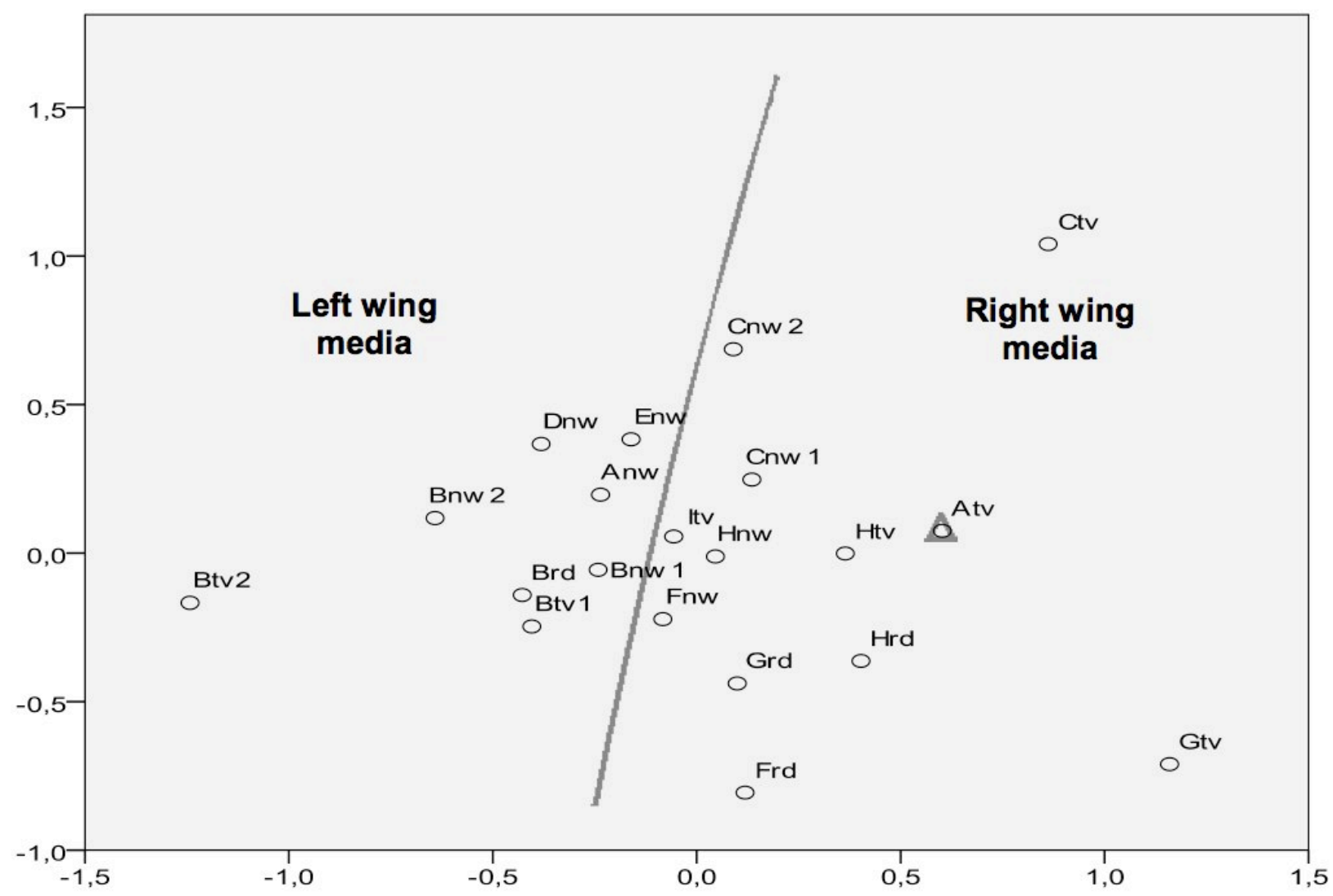


Romero-Frías, E. \& Vaughan, L. (2012). "Exploring the Relationships between Media and Political Parties through Web Hyperlink Analysis: the Case of Spain". Journal of the American Society for Information Science and Technology, 63(5): 967-976. Postprint for research purposes.

Figure 1 shows a map that is divided into two areas by a line in the middle. These two areas contain media sharing a common political orientation to left wing and right wing parties, with the exception of La Sexta (Atv). We examined the situation of Atv and found that its Web site receives the lowest number of inlinks of all the media. This could be explained by the channel's use of several active URLs over time to provide contents. There were large numbers of inlinks to each of these different URLs. The inlink counts as of 3 December 2010 were: lasexta.com $(87,200)$, lasextanoticias.com $(70,600)$, and misexta.tv $(11,400)$. The second URL was about news service only, not equivalent to the main URL. The third URL was used between 2008 and 2010 as a social platform to provide the channel's contents online. The use of multiple domains resulted in a link split and thus in lowered co-link counts. This could result in an incorrect position in the MDS map, which is based on co-link counts.

As reported earlier, the classification of political orientation of two media, Itv and Enw, was difficult and controversial. Note that their positions in Fig. 1 are very close to the line that divides left and right, reflecting the fact that their political orientation (whether left or right) is not very clear. Telecinco (Itv) occupies a central position in the map, reflecting the fact that it could be classified either as left wing or right wing, as stated in section 3.1. Its position in Fig. 1 is slightly toward the right. This placement could be used as objective evidence by people who wish to argue that Itv is right wing. In fact, among people involved in our discussion of this particular television station, a majority classified it as right wing. On the left wing side, Enw, another media that was difficult to classify, is also in a central position but slightly toward the left. This slight left-leaning position and proximity to the other Catalan newspaper in the map was expected by the experts we consulted.

In addition to the left/right division, the MDS map also shows other relationships among the media. Business newspapers (Bnw2 and Cnw2) ocuppy a less central position than general information newspapers such as El País (Bnw1) o El Mundo (Cnw1). This probably reflects the fact that they are 
specialized newspapers and thus are less connected with and less similar to general newspapers. On the left wing side, it is worth noting that the two newspapers edited in Catalonia (Dnw and Enw) appear next to each other in the map, reflecting the fact that they share a common regional perspective, despite their differing political orientation in the region.

Sogecable (Btv2) is located on the far left side of the map, a placement that could be explained by its role as an audiovisual holding of the media group Prisa. Unlike other TV media in the study, the nature of this company is different in that it does not produce any programs under its label. Instead, it broadcasted TV programs such as $\mathrm{CNN}+$ in Spanish (until $28^{\text {th }}$ December 2010) or programs from other thematic channels. The unique nature of this company could cause it to have fewer co-links with other companies and thus result in it being located far away from other media. On the right side of the map, Veo TV (Ctv) and Popular TV (Gtv) also occupy fringe positions. They are recently created media with small audiences in comparison to the other television networks included in the study.

\subsection{How political parties relate to the media (RQ2)}

To examine research question 2 (RQ2), co-link data of 20 media entities and the four national political parties were collected and analyzed together. First, two MDS maps are presented to visualize overall patterns, and then a statistical analysis is used to confirm those patterns. Fig. 2 includes all media plus the four national parties and Fig. 3 includes all media plus the left wing political party IU. The S-stress values of the MDS analysis of Fig. 2 and Fig. 3 are 0.122 and 0.136 respectively, which suggest good fits between the maps and the data. 
Romero-Frías, E. \& Vaughan, L. (2012). "Exploring the Relationships between Media and Political Parties through Web Hyperlink Analysis: the Case of Spain". Journal of the American Society for Information Science and Technology, 63(5): 967-976. Postprint for research purposes.

Figure 2. MDS map for all media and 4 national political parties

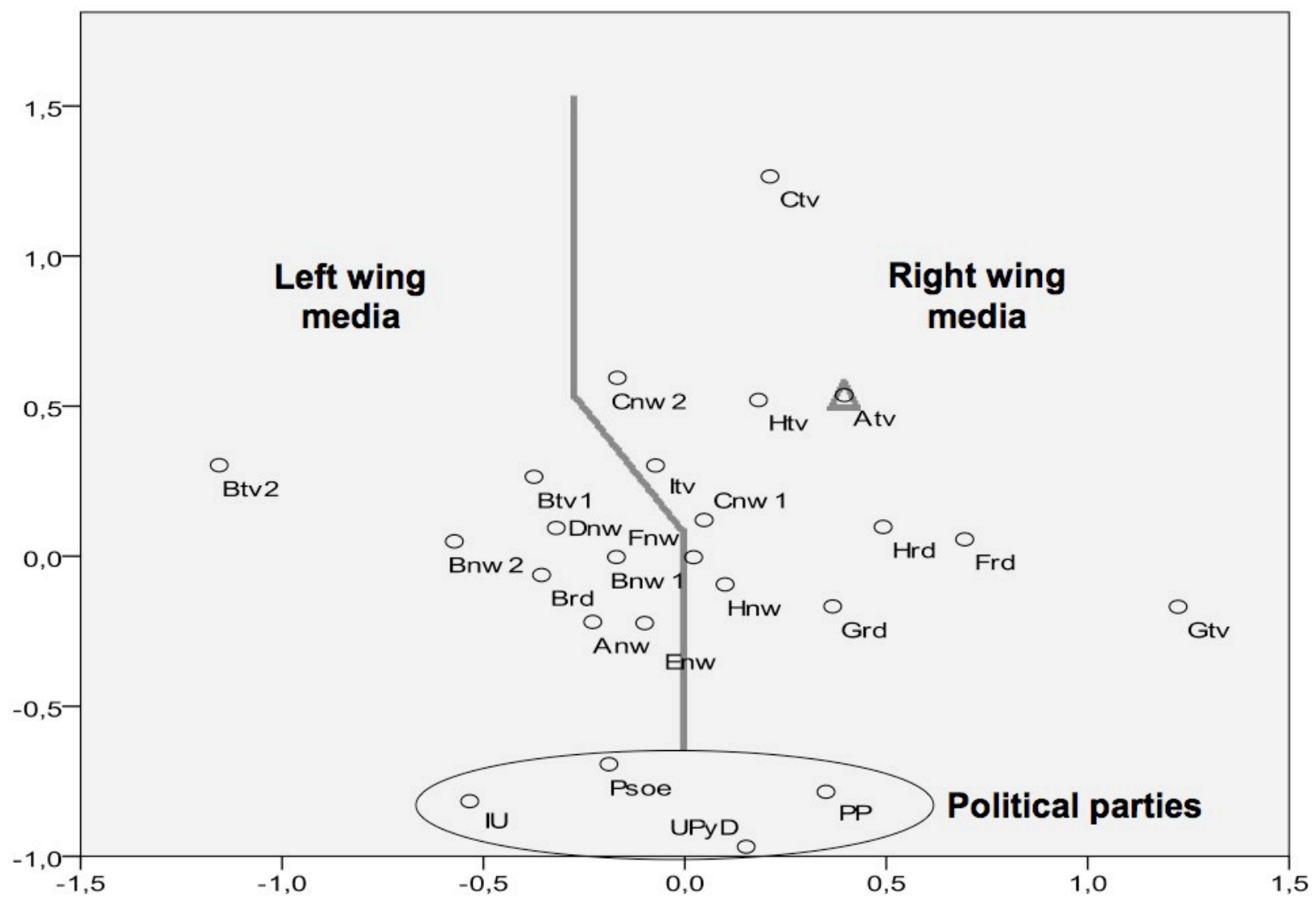

Figure 3. MDS map for all media and the left wing party IU 


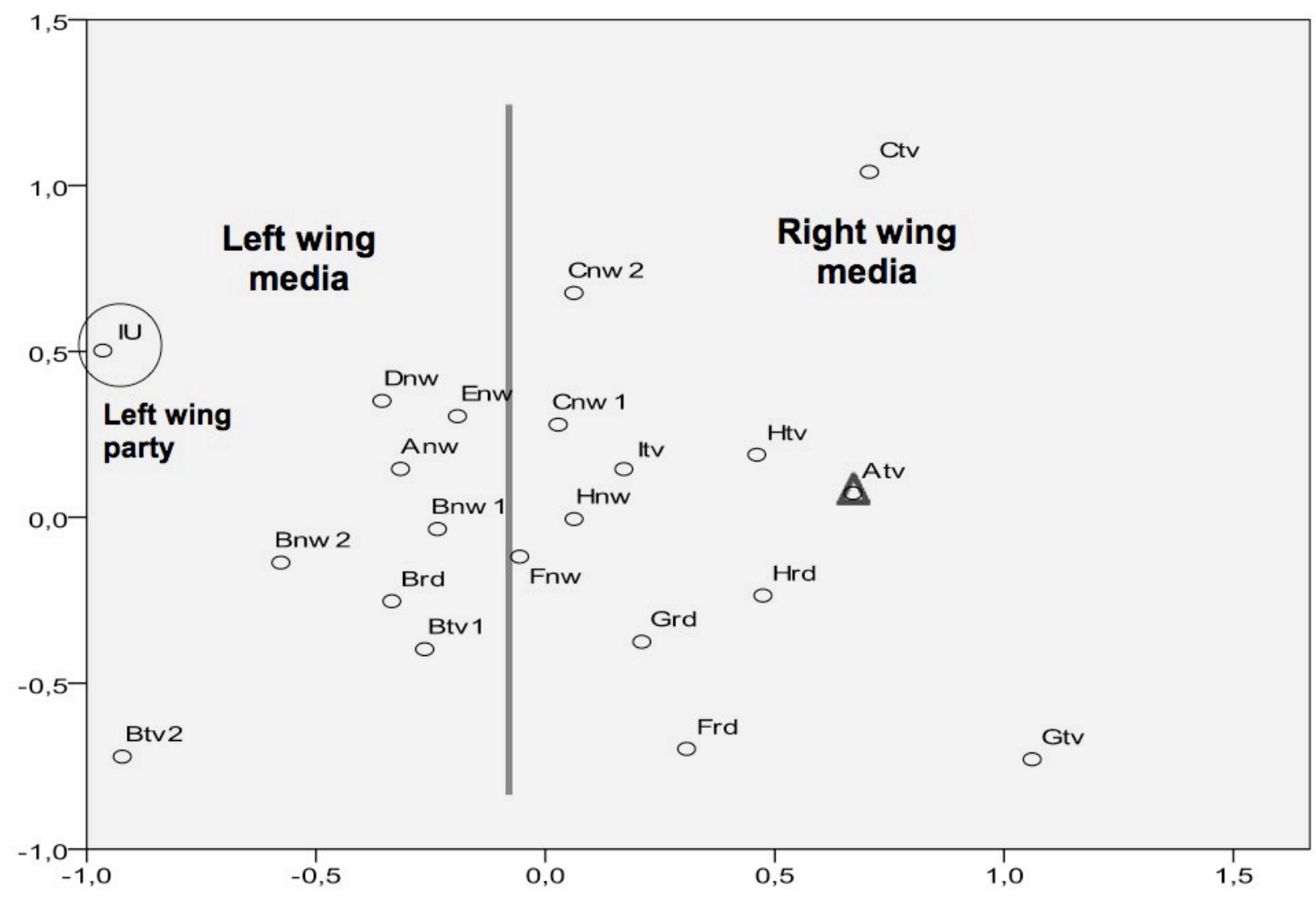

Two dimensions are clearly visible in Figure 2: the left/right dimension and the dimension of media vs. political parties (the upper vs. the lower part of Figure 2). The organizations within each cluster share common features and therefore are positioned together in the map. The media are clustered according to their political stance, divided between left wing and right wing, as was also observed in Figure 1: separate areas for the left wing and right wing media with Atv as the only exception, newspapers at the core of the map, and Itv in a central position reflecting its controversial classification. Finally, the four parties, situated in the lower part of the map, are located in order from left wing to right wing: IU (left), PSOE (center-left), UPyD (center, left/right) and PP (center-right). The position of the parties parallels the position of the media in terms of the left and right wing division. 
Additional maps with all media plus each one of the national parties were also examined. They are all broadly consistent with the findings indicated above. The most dramatic case is shown in Figure 3, in which all media plus the left wing political party IU are mapped together. Of the four parties in the study, IU is the one that departs most from a central political position and is therefore situated in the far left side of the political spectrum. Figure 3 shows that IU is located at the outskirts of the map in the left wing side, far away of media supporting right wing positions. The media hold positions similar to those in Figure 2. The main difference is that, in Figure 2, IU moved closer to other political parties due to its colinks with those parties. Nevertheless, it is located farthest left of the four parties.

An overall pattern in Figs. 2 and 3 is that the left wing media are closer to left wing parties while the right wing media are closer to right wing parties. We can thus reason that there are more co-links between media and political parties when the two are of the same orientation and fewer co-links when the two are of differing orientations. To reach a more definitive conclusion of this reasoning, we used a statistical analysis to compare the following two groups of co-links: 1. co-links between media and parties of the same orientation; 2. co-links between media and parties of differing orientations. For example, the co-link count of 23,402 between the left wing party IU and the left wing media Anw falls into the first group, while the co-link count of 8,260 between the left wing party IU and the right wing media Cnw1 belongs to the second group. Media Itv was not included in this analysis because its political orientation is not clear (see Table 2). As the political party UPyD is neither left nor right (see Table 1), it was also excluded from this analysis. As a result, there are 28 and 29 data points in group 1 and group 2 respectively. Table 5 shows the statistics for the two groups. A Mann-Whitney U test shows that there is a statistically significant difference $(\mathrm{p}=0.04)$ between the two groups. There are far more co-links between media and parties with the same political orientation (median 5,495) than there are between media and parties of differing political orientations (median 2,460). Co-links seem to be created with political orientation in 
Romero-Frías, E. \& Vaughan, L. (2012). "Exploring the Relationships between Media and Political Parties through Web Hyperlink Analysis: the Case of Spain". Journal of the American Society for Information Science and Technology, 63(5): 967-976. Postprint for research purposes.

mind, consciously or unconsciously, by page creators. This confirms an overall conclusion from this and other studies that Web hyperlinks contain useful information and can be objects of Web data mining.

Table 5. Comparison of co-link counts between the media and the parties

\begin{tabular}{|l|c|c|c|c|c|}
\hline $\begin{array}{l}\text { Political orientation of } \\
\text { the media }\end{array}$ & Number of data points & Mean & Median & Minimum & Maximum \\
\hline $\begin{array}{l}\text { Media and party are the } \\
\text { same type }\end{array}$ & 28 & $9,951.6$ & 5,495 & 14 & 52,601 \\
\hline $\begin{array}{l}\text { Media and party are of } \\
\text { different type }\end{array}$ & 29 & $3,854.7$ & 2,460 & 38 & 19,000 \\
\hline
\end{tabular}

\section{Discussion and Conclusions}

The co-link analysis found a clear pattern of linking according to a media outlet's political orientation. Media with the same political orientation tend to have more co-links than media with differing political orientations. The finding that readers prefer like-minded news (Gentzkow \& Shapiro, 2010) could explain why there are more Web pages linking simultaneously media with closer political positions. The creation of links by politicians follow the same pattern as they link sites with similar political orientation (Park \& Thelwall, 2008a). In our study, this resulted in a clear division between left wing and right wing media in the MDS map. This division is further confirmed when co-link data of political parties and media are mapped together. Left wing parties are positioned on the same side as left wing media and the same applies to right wing parties and media. A statistical analysis further confirmed that media and parties with the same political orientation tend to have significantly more co-links, e.g. there are more co-links between left wing media and left wing parties than between left wing media and right wing parties. This right/left division was found by Romero-Frías and Vaughan (2010) when studying political parties in the European Parliament. 
Romero-Frías, E. \& Vaughan, L. (2012). "Exploring the Relationships between Media and Political Parties through Web Hyperlink Analysis: the Case of Spain". Journal of the American Society for Information Science and Technology, 63(5): 967-976. Postprint for research purposes.

It should be noted that the hyperlink data only showed the clusters of media and parties. The labeling of left/right of the clusters was done based on a prior classification of political orientation of the media by experts. Although the left/right clustering of the media in Fig. 1 is further confirmed in Fig. 2 by their relationship with the political parties that have clear left/right orientation, the result is confirmative rather than definitive. In this sense, the hyperlink analysis confirms a prior knowledge rather than generating new knowledge purely based on data. This does not, however, undermine the value of the study. The fact that hyperlink data mirror offline political phenomena shows the value of the hyperlink data. It is the knowledge of the nature of hyperlinks rather than specific knowledge of the Spanish media that we aim to contribute in this academic study. To summarize, the significance of the study is twofold. First, on a practical level, the study shows that co-link data could be used to confirm the political orientation of media. Although this orientation is often known to media experts, the co-link analysis could provide objective evidence based on large scale Web data and statistical analysis without human intervention. Second, on a theoretical level, the study demonstrates that Web hyperlink data contain useful information and thus can be objects of data mining. This contributes to our knowledge of the Web. The usefulness of hyperlinks for studying political orientation was also shown by Efron (2006) which used them to determine political orientation of weblogs and web documents. The fact that media, as private business, tend not to link to competitors (Vaughan, Gao \& Kipp, 2006; Trillo Domínguez, 2008) reinforce the usefulness of co-link data for this type of study. A limitation of the study is that the sample size of 24 (20 media and four parties) is relatively small. This makes the findings from the study, particularly the results of statistical analysis of inlink counts, less generalizable. A direction of future research is to extend the scope of the study to a larger context to find out if the conclusions reached in this study still stand. A possible mean of expanding the scope of the research is to analyze media in larger countries with more media outlets. A further expansion is to examine media in multiple countries to find out how media from different countries are related. It would be very interesting and valuable to find out, for example, if there 
Romero-Frías, E. \& Vaughan, L. (2012). "Exploring the Relationships between Media and Political Parties through Web Hyperlink Analysis: the Case of Spain". Journal of the American Society for Information Science and Technology, 63(5): 967-976. Postprint for research purposes.

would still be a clear division of political orientation or if the clustering of media would occur more along lines of culture or other variables.

The current study is quantitative in nature. It does not address questions such as who made the co-links, are co-links coming from a few concentrated pages, and do those sites only link to one political orientation. A qualitative content analysis of pages that made the co-links could address these questions and would provide more insight and deeper understanding of the co-link phenemena. This is a direction of future research. 
Romero-Frías, E. \& Vaughan, L. (2012). "Exploring the Relationships between Media and Political Parties through Web Hyperlink Analysis: the Case of Spain". Journal of the American Society for Information Science and Technology, 63(5): 967-976. Postprint for research purposes.

\section{References}

Baron, D.P. (2004). Persistent media bias. Stanford University, Graduate School of Business, Research

Paper number 1845r, ". Retrieved December 6, 2010, from http://gsbapps.stanford.edu/researchpapers/library/RP1845R.pdf

Bustamante, E. (2000). Spain's Interventionist and Authoritarian Communication Policy: Telefónica as a Political Battering Ram of the Spanish Right. Media, Culture \& Society, 22(4), 433-445.

Casero-Ripollés, A. (2010). Prensa en internet: nuevos modelos de negocio en el escenario de la convergencia. El profesional de la información, 19(6), 595-601.

Chadwick, A., \& Howard, P.N. (2009). Introduction. New directions in internet politics research. In A. Chadwick \& P.N. Howard (Eds.), Routledge Handbook of Internet Politics (pp. 1-9). New York: Routledge.

Efron, M. (2006). Using Cocitation Information To Estimate Political Orientation in Web Documents. Knowledge and Information Systems, 9(4), 492-511.

Fortunati, L., Sarrica, M., O’Sullivan, J., Balcytiene, A., Harro-Loit, H., Macgregor, P., Roussou, N., Salaverría, R., \& De Luca, F. (2009). The Influence of the Internet on European Journalism. Journal of Computer-Mediated Communication, 14(4), 928-963.

Gao, Y. (2009). Gauging Public Interest from Server Logs, Surveys and Inlinks: A Multi-method Approach to Analyze News Websites. PhD dissertation. University of Western Ontario, Canada.

Gao, Y., \& Vaughan, L. (2005). Web hyperlink profiles of news sites A comparison of newspapers of USA, Canada, and China. Aslib Proceedings: New Information Perspectives, 57(5), 398-411. 
Romero-Frías, E. \& Vaughan, L. (2012). "Exploring the Relationships between Media and Political Parties through Web Hyperlink Analysis: the Case of Spain". Journal of the American Society for Information Science and Technology, 63(5): 967-976. Postprint for research purposes.

Gentzkow, M., \& Shapiro, J. (2010) What drives media slant? Evidence from US daily newspapers.

Econometrica, $78(1)$ $35-71$.

Golbeck, J., \& Hansen, D. (2011). Computing political preference among twitter followers. Proceeding of Conference on Human Factors in Computing Systems, Vancouver, Canada, May 7-12, 2011. Retrieved November 28, 2011, from http://hcil.cs.umd.edu/trs/2010-20/2010-20.pdf.

Google (2010, December 7). Links to your site, available at: http://www.google.com/support/webmasters/bin/answer.py?hl=en\&answer=55281.

Gouveia, F.C., \& Kurtenbach, E. (2009). Mapping the web relations of science centres and museums from Latin America. Scientometrics, 79(3), 491-505.

Groseclose, T., \& Milyo, J.A. (2005). Measure of Media Bias. The Quarterly Journal of Economics, 120(4), 1191-1237.

Hallin, D., \& Papathanassopoulos, S. (2002). Political clientelism and the media: southern Europe and Latin America in comparative perspective. Media, Culture \& Society, 24(2), 175-195.

Jenkins, H. (2006). Convergence Culture: Where Old and New Media Collide. New York: New York University Press.

Kim, J.H., Barnett, G.A., \& Park, H.W. (2010). A Hyperlink and Issue Network Analysis of the United States Senate: A Rediscovery of the Web as a Relational and Topical Medium. Journal of the American Society for Information Science and Technology, 61(8), 1598-1611.

Lang, P., Gouveia, F.C., \& Leta, J. (2010). Site co-link analysis applied to small networks: a new methodological approach. Scientometrics, 83(1): 157-166. 
Romero-Frías, E. \& Vaughan, L. (2012). "Exploring the Relationships between Media and Political Parties through Web Hyperlink Analysis: the Case of Spain". Journal of the American Society for Information Science and Technology, 63(5): 967-976. Postprint for research purposes.

Norušis, M. (2010). PASW® Statistics 18 Advanced Statistical Procedures Companion. Upper Saddle River, NJ: Prentice Hall.

Ortega, J., \& Aguillo, I. (2008). Visualization of the Nordic academic web: Link analysis using social network tools. Information Processing \& Management, 44(4), 1624-1633.

Park, H.W., (2010). Mapping the e-science landscape in South Korea using the webometrics method. Journal of Computer-Mediated Communication, 15 (2), 211-229.

Park, H.W., \& Thelwall, M. (2008a). Link analysis: Hyperlink patterns and social structure on politicians' Web sites in South Korea. Qual Quant, 42, 687-697

Park, H. W., \& Thelwall, M. (2008b). Developing network indicators for ideological landscapes from the political blogosphere in South Korea. Journal of Computer-Mediated Communication. 13 (4), 856-879.

Park, H.W., \& Kluver, R. (2009). Trends in online networking among South Korean politicians. Government Information Quarterly, 3, 500-515.

Paterson, C., \& Domingo, D. (Eds.). (2008). Making online news: The ethnography of new media production. New York: Peter Lang.

Romero-Frías, E., \& Vaughan, L. (2010). "European Political Trends Viewed Through Patterns of Web Linking”. Journal of the American Society for Information Science and Technology, 61(10), 2109-2121.

Sampedro Blanco, V. (Ed.). (2008). Medios y elecciones 2004: La campaña electoral y las "otras campañas”. Madrid: Editorial Universitaria Ramón Areces / Servicio de Publicaciones Universidad de Granada. 
Romero-Frías, E. \& Vaughan, L. (2012). "Exploring the Relationships between Media and Political Parties through Web Hyperlink Analysis: the Case of Spain". Journal of the American Society for Information Science and Technology, 63(5): 967-976. Postprint for research purposes.

Sampedro Blanco, V., García Luengo, O., Vizcaíno Pérez, R., \& Trenzado Romero, M. (Ed.). (2008). Televisión y urnas 2004: Políticos, periodistas y publicitarios. Madrid: Editorial Universitaria Ramón Areces / Servicio de Publicaciones Universidad de Granada.

Smith, A., \& Thelwall, M. (2002). Web Impact Factors for Australasian universities. Scientometrics, 54, 363-380.

Tang, R., \& Thelwall, M. (2003). U.S. academic departmental web-site interlinking in the United States: Disciplinary differences. Library \& Information Science Research, 25(4), 437-458.

Thelwall, M., \& Wilkinson, D. (2004), Finding similar academic Web sites with links, bibliometric couplings and colinks. Information Processing \& Management, 40(3), 515-526.

Tremayne, M. (2004). The web of context: applying network theory to the use of hyperlinks in journalism on the web. Journalism and Mass Communication Quarterly, 81(2), 253-73.

Trillo Domínguez, M. (2008). Análisis cibermétrico de la prensa digital española. Ranking de calidad web y mapa de influencia mediática. PhD dissertation. University of Granada, Spain.

Vaughan, L., \& Romero-Frías, E. (2010). Web hyperlink patterns and the financial variables of the global banking industry. Journal of Information Science, 36(4), 530-541.

Vaughan, L., Gao, Y. \& Kipp, M. (2006). Why are hyperlinks to business Websites created? A content analysis. Scientometrics, 67(2), 291-300

Vaughan L., Tang, J. \& Du, J. (2010). Constructing business profiles based on keyword patterns on Websites. Journal of the American Society for Information Science and Technology, 61(6), 1120-1129. 
Romero-Frías, E. \& Vaughan, L. (2012). "Exploring the Relationships between Media and Political Parties through Web Hyperlink Analysis: the Case of Spain". Journal of the American Society for Information Science and Technology, 63(5): 967-976. Postprint for research purposes.

Vaughan, L., \& You, J. (2006). Comparing business competition positions based on Web co-link data: The global market vs. the Chinese market. Scientometrics, 68(3), 611-628.

Vaughan, L., \& You, J. (2010). Word co-occurrences on Webpages as a measure of the relatedness of organizations: a new Webometrics concept. Journal of Informetrics, 4(4), 483-491.

"This is the peer reviewed version of the following article: Romero-Frías, E.; Vaughan, L. Exploring the Relationships between Media and Political Parties through Web Hyperlink Analysis: The Case of Spain. Journal of the American Society for Information Science and Technology, 63(5): 967-976 (2012), which has been published in final form at http://dx.doi.org/10.1002/asi.22625. This article may be used for non-commercial purposes in accordance with Wiley Terms and Conditions for Self-Archiving." 